The Book of Fermentology

\title{
The Evolution of Sour Taste in Hominids [enriched transcript]
}

Rob Dunn ${ }^{1}$

${ }^{\mathbf{1}_{\text {North }} \text { Carolina State University }}$

NC State University Libraries

Published on: Dec 03, 2021

License: Creative Commons Attribution 4.0 International License (CC-BY 4.0). 
Editors note: This publication contains the video of the talk from the Fermentology webinar series, as well as a lightly edited transcript of the lecture. The transcript has been enriched with media, annotations, and links to other material by the digital publication team in order to amplify and extend the content for a reading experience.

\section{Abstract}

Rob Dunn is a Fermentology co-founder and professor in the Department of Applied Ecology at NC State University. He is also the co-author of Delicious: The Evolution of Flavor and How It Made Us Human, with Monica Sanchez, which considers the role of flavor in our human story. In his talk, Rob Dunn discusses the intersection between fermentation and flavor, focusing on the ways in which smell and taste may have allowed our ancestors to begin to distinguish safe ferments from dangerous ones long before they could even speak.

\section{Watch the talk}

\section{Visit the web version of this article to view interactive content.}

\section{The Evolution of Sour Taste in Hominids with Rob Dunn}

\section{Introduction}

If we think about the big story of humans, there are some fields in which flavor has always been central or has been episodically central. If we think, for example, about writers and artists, they often put flavor and deliciousness in the center of their works. This is true with the transition from portraits and landscapes to still life paintings.

The birth of still life paintings represents an amazing moment in art history in which one goes from having Jesus, Mary, queens or kings at the center of things to plums at the center of things. 


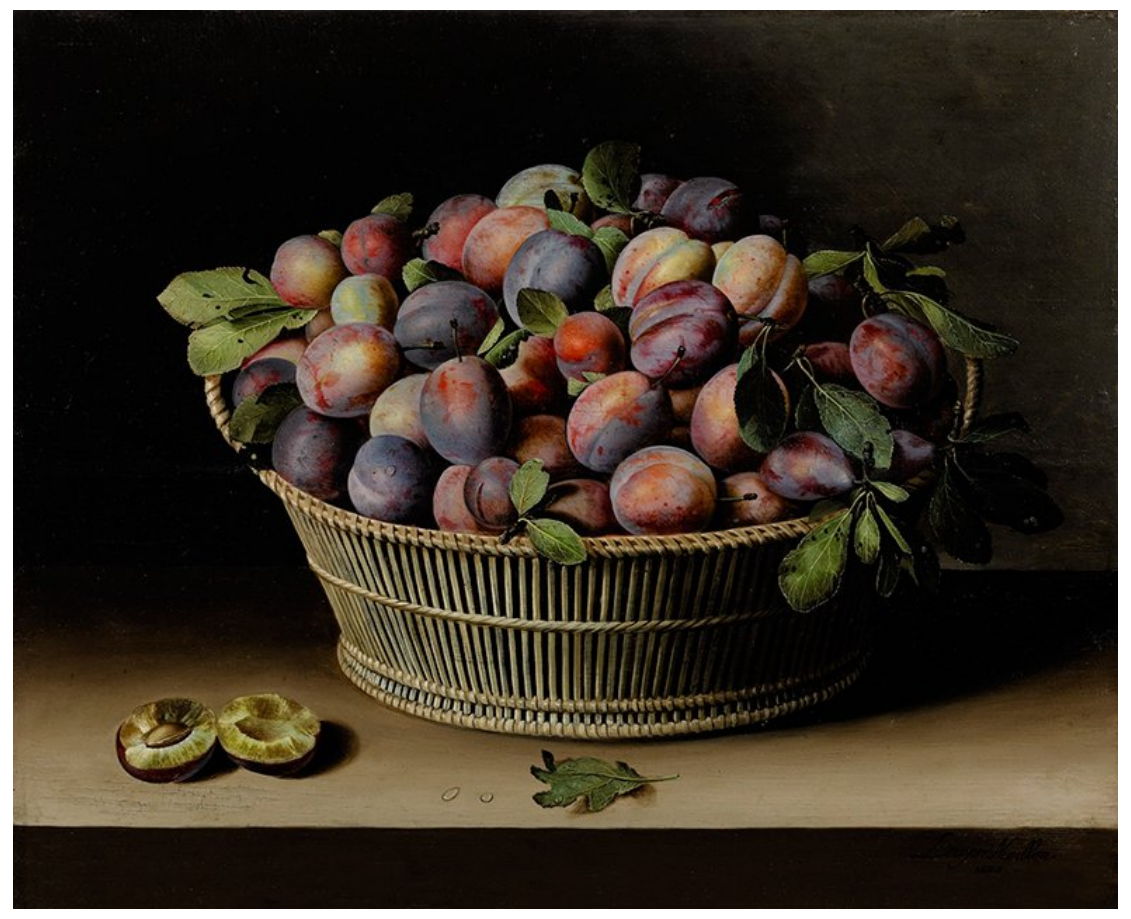

Still Life with Basket of Plums by Louyse Moillon from Wikimedia Commons.

It also happens in poetry. I'll begin by sharing a couple of poems that are germane to the main points I'll be making today, both by William Carlos Williams.

\section{This is Just to Say[1]}

I have eaten

the plums

that were in

the icebox

and which

you were probably

saving for breakfast.

Forgive me.

They were delicious

so sweet

and so cold.

\section{To a Poor Old Woman[2]}

munching a plum on

the street a paper bag 
of them in her hand

They taste good to her.

They taste good

to her. They taste

good to her

You can see it by

the way she gives herself

to the one half

sucked out in her hand

Comforted

a solace of ripe plums

seeming to fill the air

They taste good to her.

I think it's germane to begin here because in our new book, Monica Sanchez and I attempt to revisit the human story with the same attention to flavor and deliciousness that Williams offers the plum. In short, we consider why it tastes good to her, but also why it matters. Our argument throughout the book is that in many of the key transitions in human evolution, flavor played a role. When confronted with a more delicious food and a less delicious food, our ancestors tended to choose the more delicious food. They chose what tasted good to them. From such choices, much follows. In the book we consider this argument in the context of a series of mysteries-- stick tools, big brains, fire, culinary traditions, extinctions, avocados, fermentation, spice use, art, food sharing, and more. More or less, these mysteries map onto the chapters in the book. But today, I'll be focusing on two chapters.

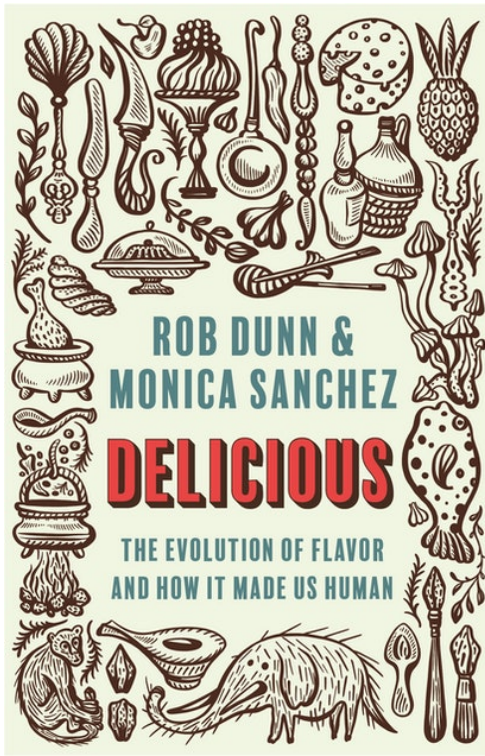

Book cover of Delicious: The Evolution of Flavor and How It Made Us Human, by Rob Dunn and Monica Sanchez, Princeton University Press 2021.

I want to begin with culinary traditions. It is these traditions that really set the stage for a lot of what we've been learning about in the Fermentology lecture series. Culinary traditions are quite ancient. We infer that they're ancient because some of our closest relatives also have them. For example, chimpanzees have culinary traditions. These are often manifest in the context of their tool use. Below, we can watch a video from my colleagues at the 
Max Planck in Leipzig. The video shows a variety of kinds of tool use by chimps, most of them having to do with food.

\section{Visit the web version of this article to view interactive content.}

\section{Human impact on chimpanzee behavior}

This tool use is amazing for many reasons. It's a window into how our ancestors might have used stone tools and stick tools, even before they made things like spears or scrapers. But it also is a window into what might have been going on with our ancestors with regard to culinary cultures. To put this in context, we can look at an evolutionary tree of humans and our closest living relatives. What we know about these relatives is that orangutans, gorillas, chimpanzees, and humans all use tools for various food-related things. Chimpanzees and humans use them often. It's typically inferred that our common ancestors also used them often.

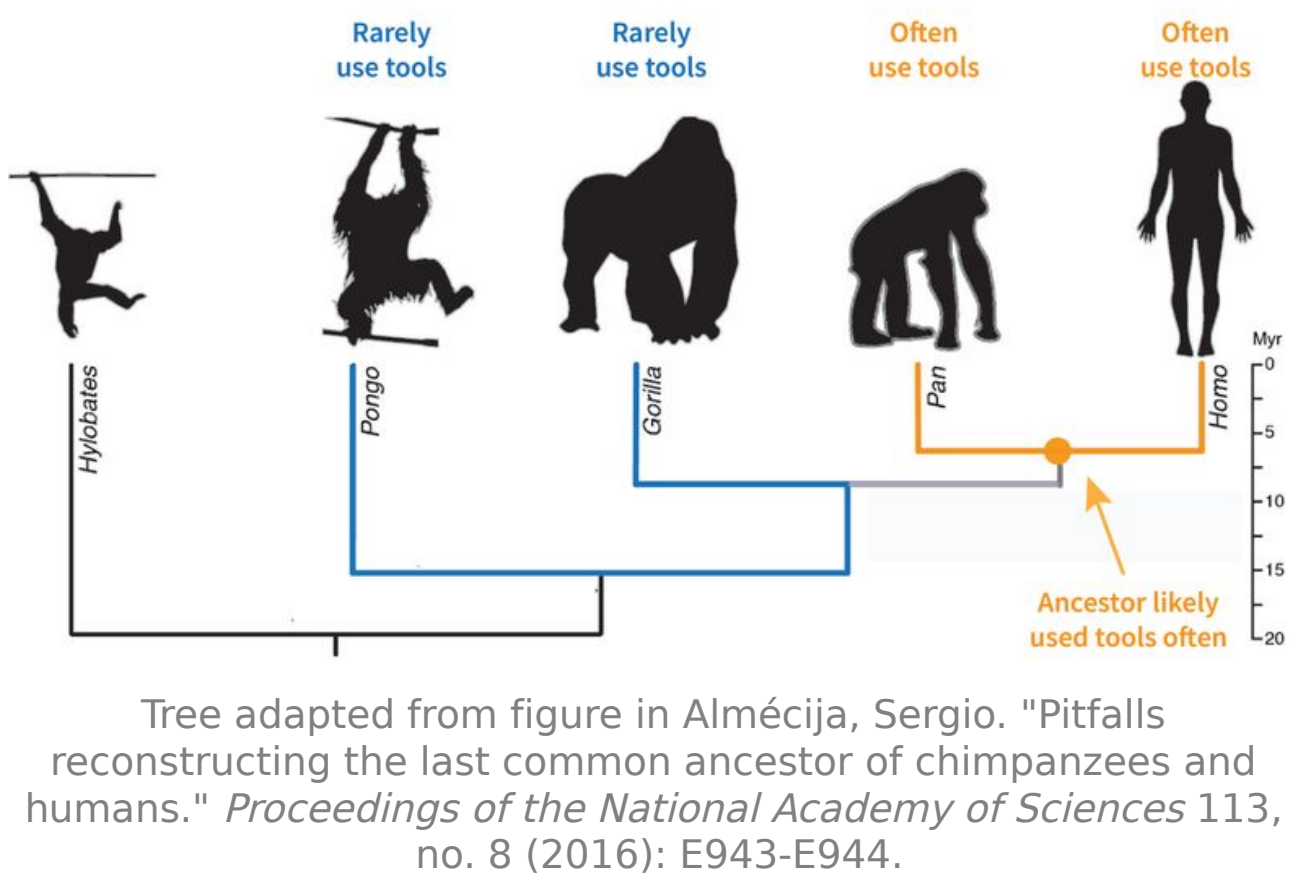

What's not as often described about this reality is that the ways in which different populations of chimpanzees, and almost certainly our ancestors, use tools can vary for reasons having to do with the environment, but can also vary in ways that seem to have nothing to do with the environment and are just due to tradition. For example, Jane Goodall studied chimpanzees at the Gombe National Park site. Toshisada Nishida 
studied chimpanzees, during roughly the same time period, at Mahale Mountain National Park, a little bit farther south.

These two sites are very, very similar with regard to their plants and also with regard to their animals, including insects such as ants.

Despite this, the chimpanzees at the two sites eat different things. One of the most conspicuous cases of this relates to ants. At the site that Jane Goodall did most of her work at, the chimpanzees used stick

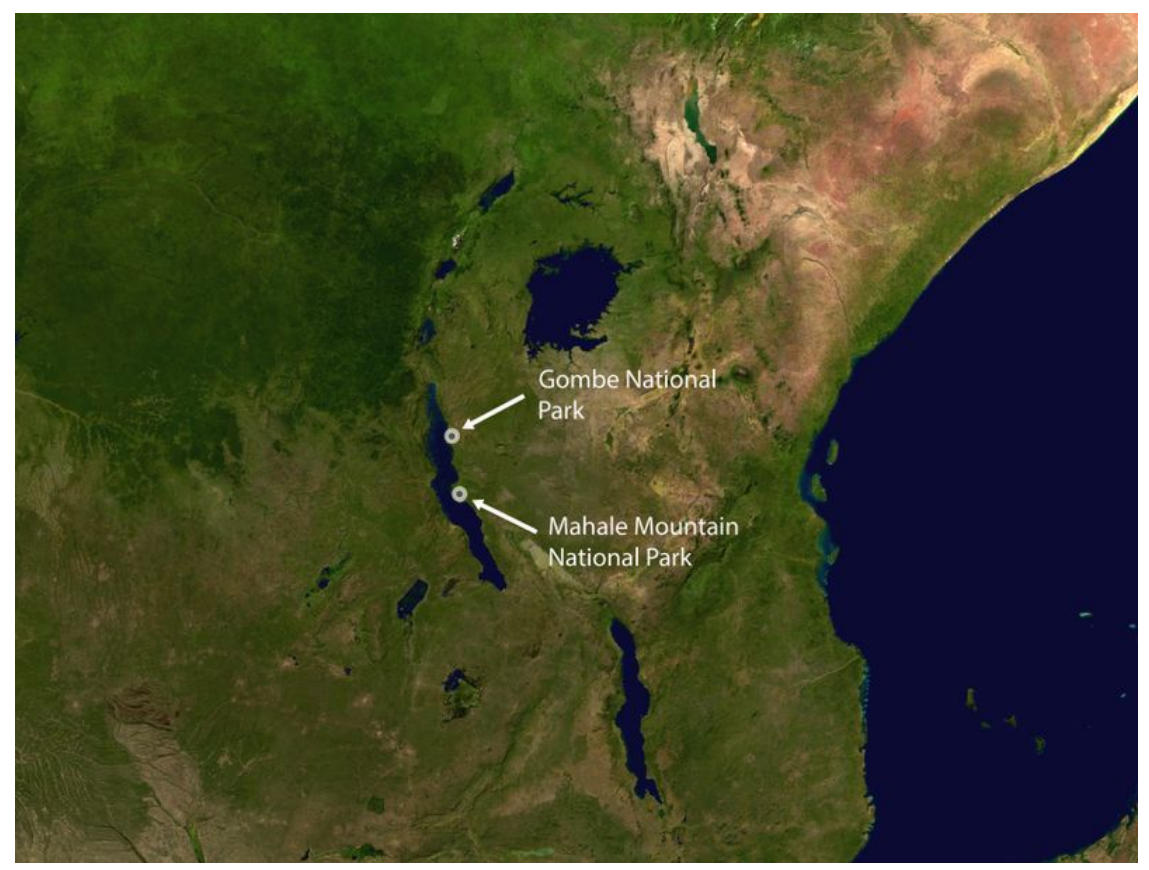

Base composite image of Africa from NASA tools to eat Crematogaster ants and army ants (Dorylus spp.). In contrast, at Mahale, chimpanzees in a near identical environment eat carpenter ants (Camponotus spp.), using stick tools. And this has been true for decades. And this is attributed to culinary traditions. They've just learned to eat these different things. That's what their group does.

\section{Visit the web version of this article to view interactive content.}

The more we compare populations of chimpanzees, the more it seems to be the case that there are often these culinary traditions that have nothing to do with the environment, or at least, they're not exclusively determined by the environment. The question becomes, how does this happen? It's interesting to ask this question because while culinary traditions offer are lasting cultural adaptations to new environments, they also lead different populations to eat different foods in similar environments. If we think about our own ancestors moving around the world to different climates, whatever is at play in these culinary traditions would have been super important in 
such movements and with regard to the new foods that they adopted in these different places. So what's going on? How does it happen?

To answer, I need to give a quick little glossary of the different aspects of flavor and what's going on with the mouth. The way I'll define these terms is the way that food scientists define them. It's not necessarily the way we use them in our day-to-day lives. These terms include: taste, mouth-feel, retronasal aromas, chemesthesis, and flavor. Taste in this context is a series of sensations associated with taste receptors on the tongue, including sour, sweet, bitter, umami, maybe kokumi. These tastes are really a sensory guide toward things we need and away from things we don't need. Mouthfeel is the sense of touch in the mouth. And we tend to think this sounds silly. Mouthfeel is the most ridiculous sounding aspect of flavor. And yet, it's potentially very important. A big part of the joy that comes from eating a fatty avocado is about the mouth-feel. Retronasal aromas are the aromas of foods once they're in our mouths. When they're lightweight, chemicals go up into the backs of our noses from our mouths.

Chemesthesis is the sense associated with spicy foods, but also cooling foods like menthol. Flavor is a composite of all of these sensations (along with others). With regard to cultural traditions, my argument is that flavor in general is important, but that retronasal aromas are disproportionately important. Retronasal aromas are not the only kind of aromas. In fact, they're not even the one we most often think about. The kind of aromas we most often think about are orthonasal aromas associated with orthonasal olfaction. This is what happens when a dog sniffs the world. A dog blows air out of its nose. It disrupts smell molecules on the ground. And then it sniffs in and inhales. Those molecules go back up into its nose and are detected by olfactory receptors. That's orthonasal olfaction. But retronasal olfaction is different. It happens once foods are in our mouths. When a man eats a hamburger, he's probably getting a little bit of orthonasal olfaction, getting some bun smell that's coming up through his nose. But the majority of what he's experiencing is the retronasal olfaction. 


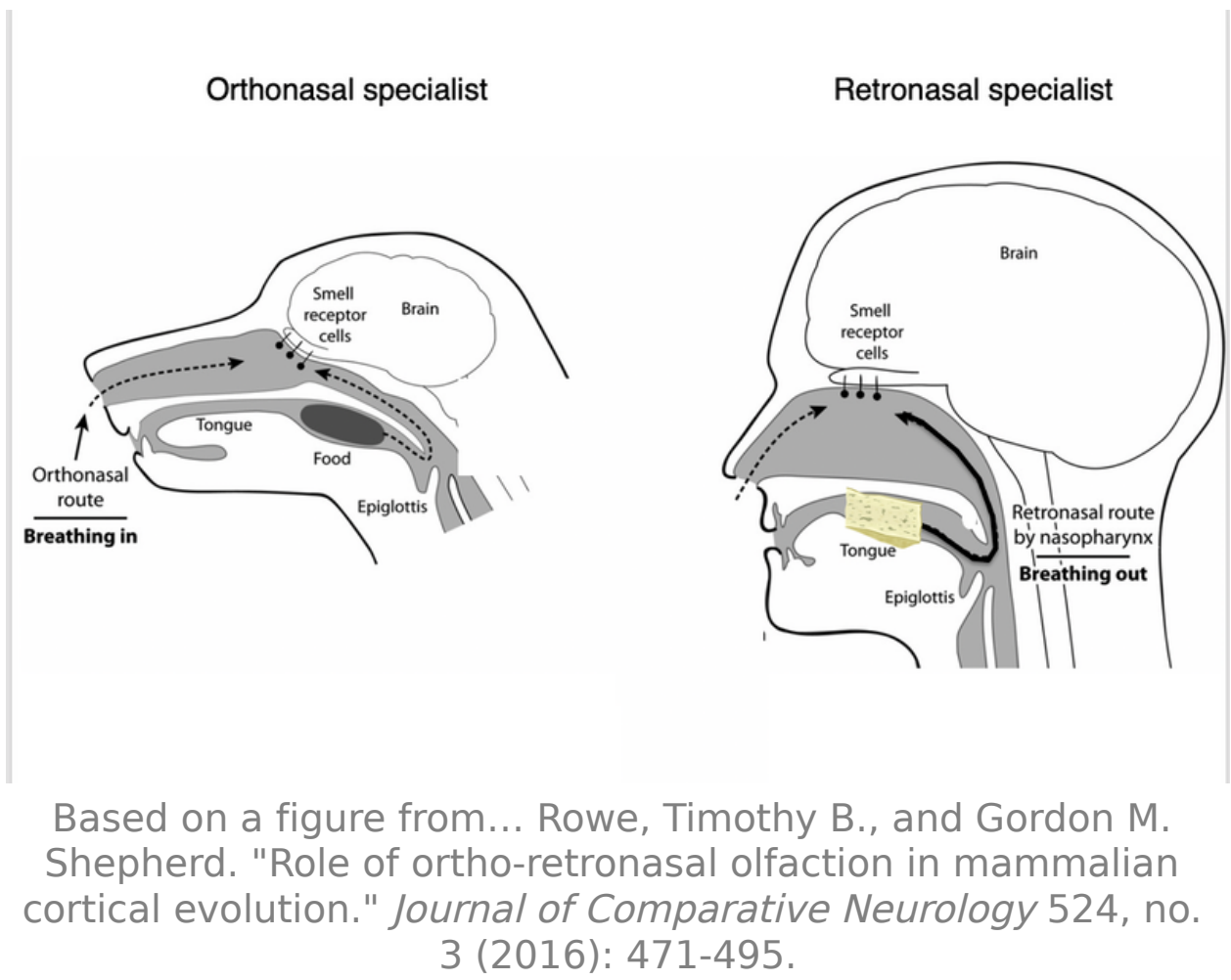

Daniel Lieberman and Gordon Shepherd have both argued-- and we consider this argument in the book-- that humans are really specialists in retronasal olfaction, especially compared to dogs. Dogs are specialists in orthonasal olfaction. Dogs are really good at sniffing the world in front of them. We're really good at sniffing a piece of cheese that's on our tongue. This becomes really important because the system of olfaction is connected to our brains in really, really amazing and intricate ways that suggest, in some ways, it's maybe the most important sense to us in terms of how we make sense of the world. I liken it to a card catalog, which I know makes me seem old, but I think it's the right analogy. It used to be the case that you would go to a library. There was a card catalog for subjects. There was one for titles, and there was one for authors. And maybe in some libraries, there were additional

groupings. You would look for the subject you wanted, or the title you wanted, or the author you wanted. You could see related books or alphabetically related books on subsequent cards. Something similar happens in our brain, although it's a little bit more elaborate. Each time we smell something, that experience receives two cards. One card is associated with something like the title of the experience, a story recorded as a memory. For example, "I was eating cheese with my friend" and whatever happened next. The second card records the subject as "cheese" in this case. So there are these two cards that help to organize the experience of olfaction. The more 
varied experiences accumulate in a particular subject, the more the subject cards are divided. Cheeses become divided into hard and soft cheeses. Then soft cheeses become divided into blue cheeses and, for example, washed-rind cheeses, and so on. An expert is somebody who can distinguish the many types of a food and so whose card catalog has many divisions. You can think about this in your own life. In some fields, or in some foods, you likely have a broad category. A student in my class-- when we brought in a bunch of cheeses to smell, stated that all the cheeses smelled like cheesy potato chips. Very broad category. You also have things in which you likely have narrower categories. Each of us builds these categories and subcategories. But the super interesting thing-- and I think that's really important for us in terms of making sense of the world as we explore-- is that there's this third element. Each experience is assigned a level of pleasurableness, such that smells that are always associated with pleasurable experiences become good smells. Smells associated with bad experiences become bad smells. In essence, it's a review of the book, or it's a Yelp system for the nose. As far as neuroscientists understand, there are no intrinsic "goods" or "bads" in olfaction (With taste, there are. With taste, your tongue is always leading you towards sweet and leading you away from bitter.). With olfaction, the thinking is that none of this is innate, or at least none of it is genetic. So you could learn to love a skunk, and you could learn to hate lavender. This is not how ecologists see the world. It's the neuroscience understanding of what's going on. Where this becomes really interesting is that this is, in essence, a ranked library of the world that we can imagine our ancestors using as they went out around the world to categorize things, to make sense of them, and to sort good from bad, delicious from not delicious in ways that were incredibly beneficial. That would have worked, for example, in the chimpanzee context, even before our ancestors could speak, much less write. All of this begins really early in life- remarkably early. There's an amazing set of studies done by Benoist Schaal and other scholars looking at when we start to learn to love some smells and learn to dislike others. One series of studies has focused on pregnant mothers. For example, Schaal did a study where he compared mothers who were eating anise and not eating anise. He made sure that the mothers who were assigned to not eating anise, didn't eat anise while they were pregnant. The mothers who were supposed to eat anise ate lots of it. When the babies were born, he compared how they reacted to anise, based on whether or not their mothers had eaten it while pregnant. You can't ask a three-hour-old baby whether they like or dislike something. Instead, he looked at their faces. He would put a little cotton swab in front of their face that either had anise on it or didn't have anise on it. He would then look at whether they made a scrunchy face (associated with displeasure) or a lip-licking face 
(associated with pleasure). Lots of these studies have now been done, but this one is particularly telling. When babies whose mothers ate anise were presented with the anise Q-tip, that they were much more likely to lick their lips and to make faces as though they wanted to nurse, and to do this for longer time periods. In contrast, the babies whose mothers did not eat anise - they reacted the same with regard to liplicking as they would have as if there was nothing on the Q-tip. In contrast, when looking at scrunchy facedness, the babies whose mothers were anise eaters almost never showed a scrunchy face in response to anise smells. And the babies whose mothers were not anise-eaters were far more likely to show a scrunchy face and to do so for longer time periods.
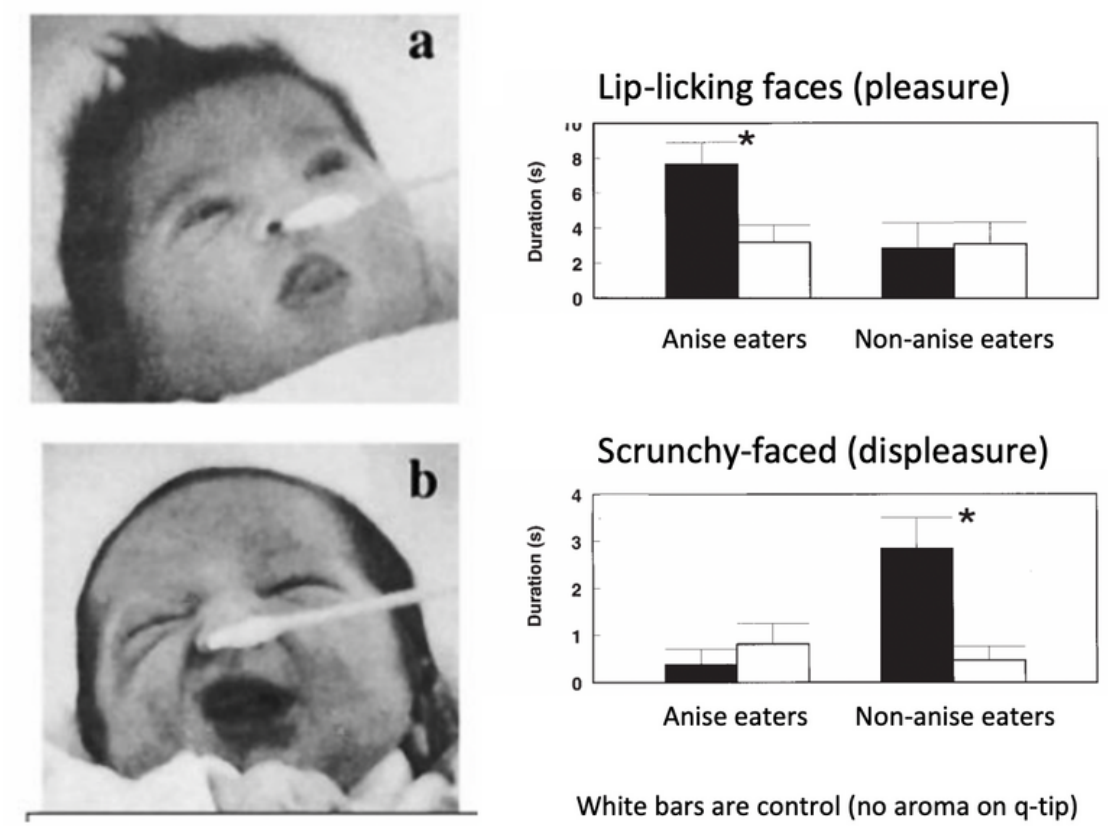

Images and figures adapted from Schaal, B., Marlier, L., \& Soussignan, R. (2000). Human foetuses learn odours from their pregnant mother's diet. Chemical senses, 25 6, 72937 .

This has now been shown to be the case for garlic, for fermented fish, for some vegetables, and for blue cheese. In every case, if your mother eats something while she's pregnant with you, you are born liking that thing, contingent it's the right kind of chemical. So it's as though our mothers' bodies are teaching us "what I eat is good to eat".

Now, think about our ancestors moving out across the world. The first generation arrived in a new habitat, be it the tundra, the desert, or the rainforest, and they would 
have had to sort through things anew. But the second generation would have already learned which things to like and which things not to like at birth. Therefore, this is a built-in way to rapidly establish culinary traditions.

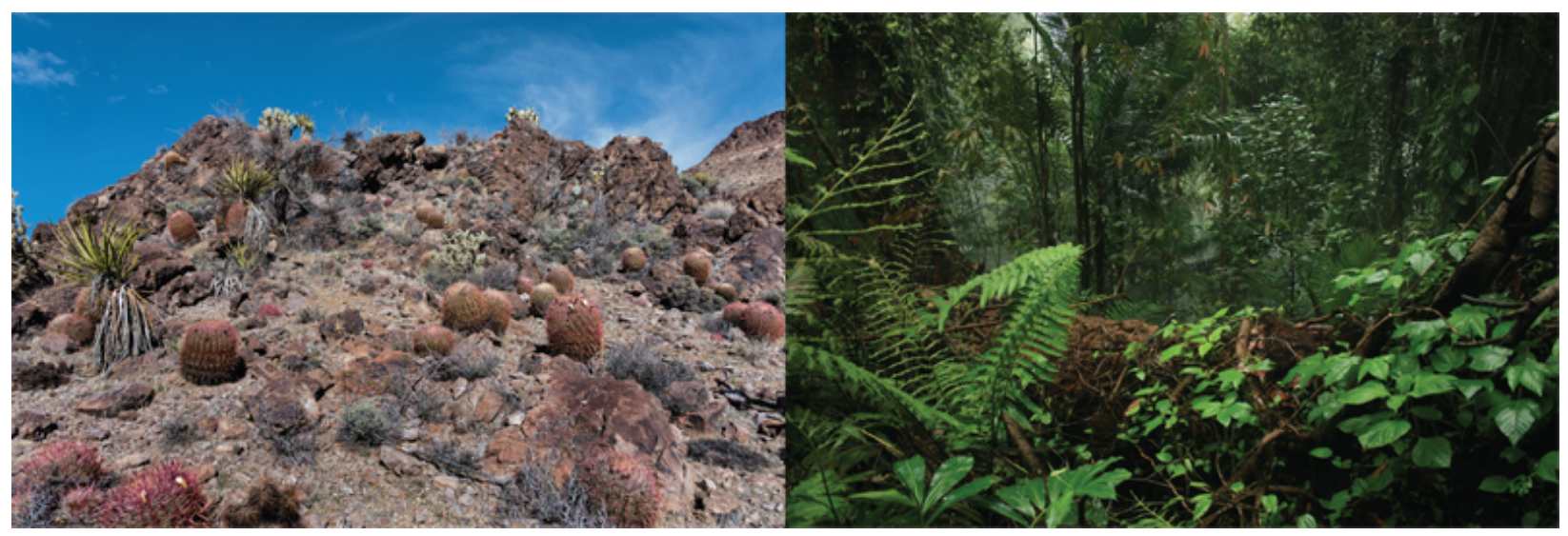

Left: Mojave desert plant life, John Fowler, CC BY 2.0. Via Flickr. Right: Rainforest image by_Adam Greig.

We can imagine this was fast forwarded once our ancestors could talk and could more easily communicate, "this tastes so good!", "this makes me happy", "this is what I love to eat when I'm around you". This culinary tradition component is therefore very important and is at the root of the creation of new foods, especially once our ancestors start not only to look for new foods, but actually to make foods. $\underline{\text { A poem by_Jane }}$ Hirshfield is really evocative here. She writes:

\section{My Species}

even

a small purple artichoke

boiled

in its own bittered

and darkening

waters grows tender,

grows tender and sweet

patience, I think,

my species

keep testing the spiny leaves

the spiny heart 
And so you test the spiny leaves in one generation. But the next generation is already born knowing the right way to eat them or how to feel when they're prepared in the right way. This, then, becomes very important as we think about one of the forms of creation most important to our group-- fermentation.

Fermentation, as I'll consider it today, has two mysteries. The first mystery asks, when does the control of fermentation begin? Here, I'm thinking about fermented foods in the broadest context. It includes cheese, fermented fish, beer, wine, cider, kimchi, sauerkraut, leavened bread, garum, soy sauce, fish paste, kombucha, cured ham, and literally thousands and thousands of other foods united by the reality that they've been transformed, which is to say created through the control of microbes. The second mystery is, how do we control this? And does this culinary culture or culinary tradition phenomenon play a role?

First, with regard to when this starts, we've actually seen a lot already in this talk series about the beginnings of fermentation. In the classic story of fermentation and the classic story of our diets, our history looks something like this: Maybe 8 million years ago, we begin to use stick tools. We then have a long period of reliance on fruit, leaves, maybe roots and insects. Stone tools turn up about 2.3 million years ago. About 1.9 million years ago, our brains get way bigger, our teeth start getting smaller. Something important in the culinary world happens there. A million years ago or maybe earlier, Richard Wrangham is right. Fire becomes part of our story. And then we get agriculture, and then we get beer, and then things stop.

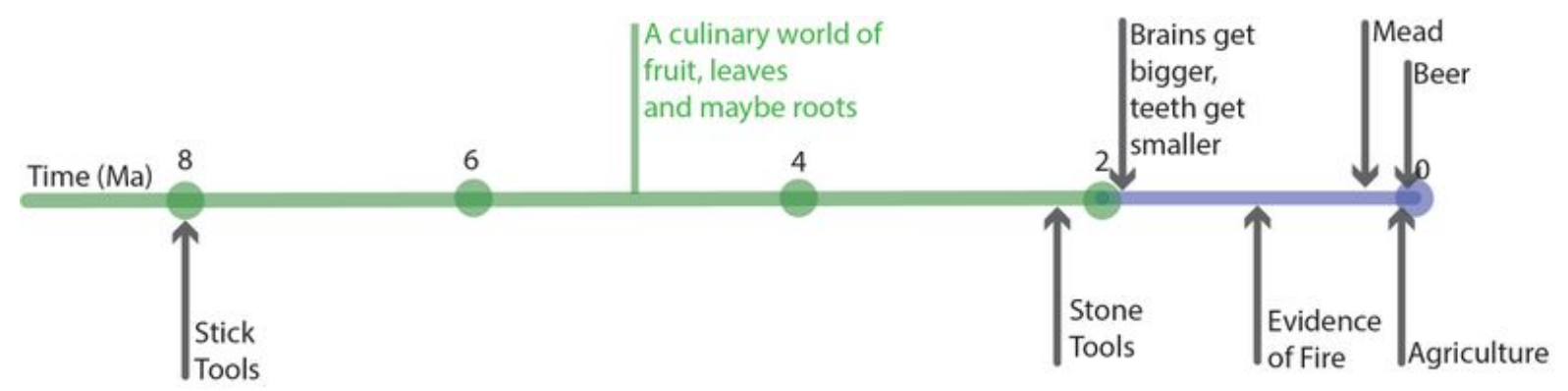

It's been known for a long time that maybe the story was more complex. For one, when we look at the importance of fermentation and those time periods in which we know a lot, fermentation seems really central. It doesn't seem like an add-on. We saw this in Tate Paulette's amazing talk on early beers. We also know it from other contexts. The other thing we're starting to see is that the more we look, the more evidence we find for early fermentations. For example, it's now been argued by Neil Rusch, who gave a 
talk earlier in the Fermentology series, that mead was made much, much earlier than the onset of agriculture. We began to form the microbes associated with mead before we began to farm grains. As for beer... It, too, now seems to have emerged earlier than originally believes. Li Liu at Stanford recently published a study suggesting that in what is now Israel, there's evidence of barley malting and fermentation going back 13,000 years before agriculture arrives in the same area. []]

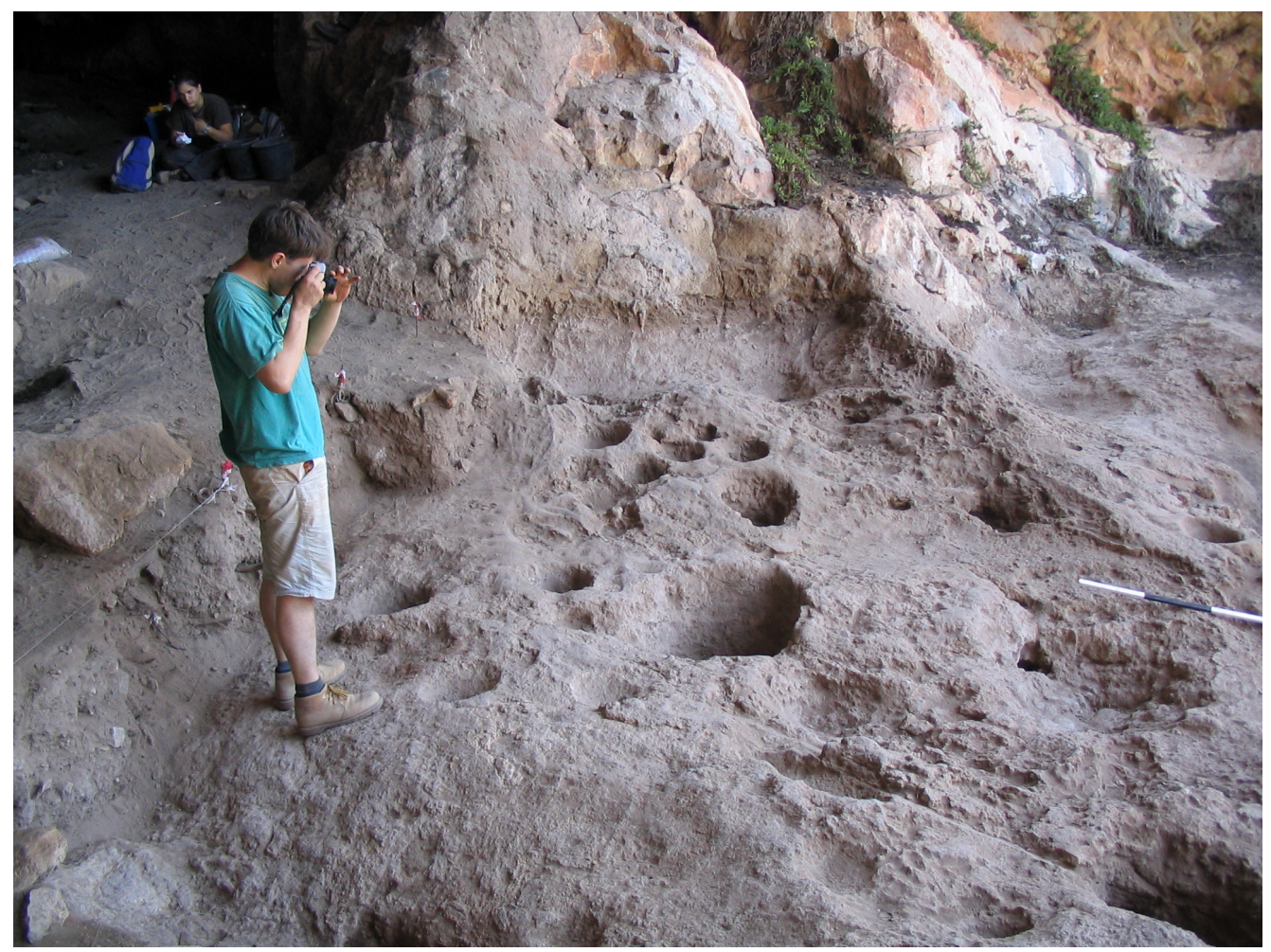

Natufian bedrock mortars in Raqefet Cave, Mount Carmel, Israel, part of Raqefet excavation in 2004. Image by Dani Nadel, CC BY $\underline{3.0}$ from Wikimedia Commons.

All these dates are being pushed back and are allowing us to think about fermentation as being earlier than agriculture. Earlier in the series, Amaia Arranz Otaegui and Lara Gonzalez Carretero talked about the pre-history of bread and, in fact, found bread that clearly pre-dates agriculture, the open question being whether or not the bread was being fermented. We don't know. Katie Amato talked about the possibility that fermentation might actually be much, much older. That perhaps it begins with Homo erectus. Maybe it's 1.9 million years old. Maybe it's what allowed for bigger brains in the first place and catapulted us to our current moment. One thing about this story that I think is especially fascinating - which Katie highlights in her talk and we also highlight in the book - is the evidence. If you look across primates, you actually see much more use of fermentation and control of fermentation than anybody thought 
before. Katie highlighted an example with work by Liz Mallott that observed capuchin monkeys that knock down fruits intentionally and then come back to them weeks later when they're fermented. This really begs the question: if the capuchin monkeys can do this, could our own ancestors have done it long before they began to control other aspects of their environment? We don't know. But it's interesting to think about.

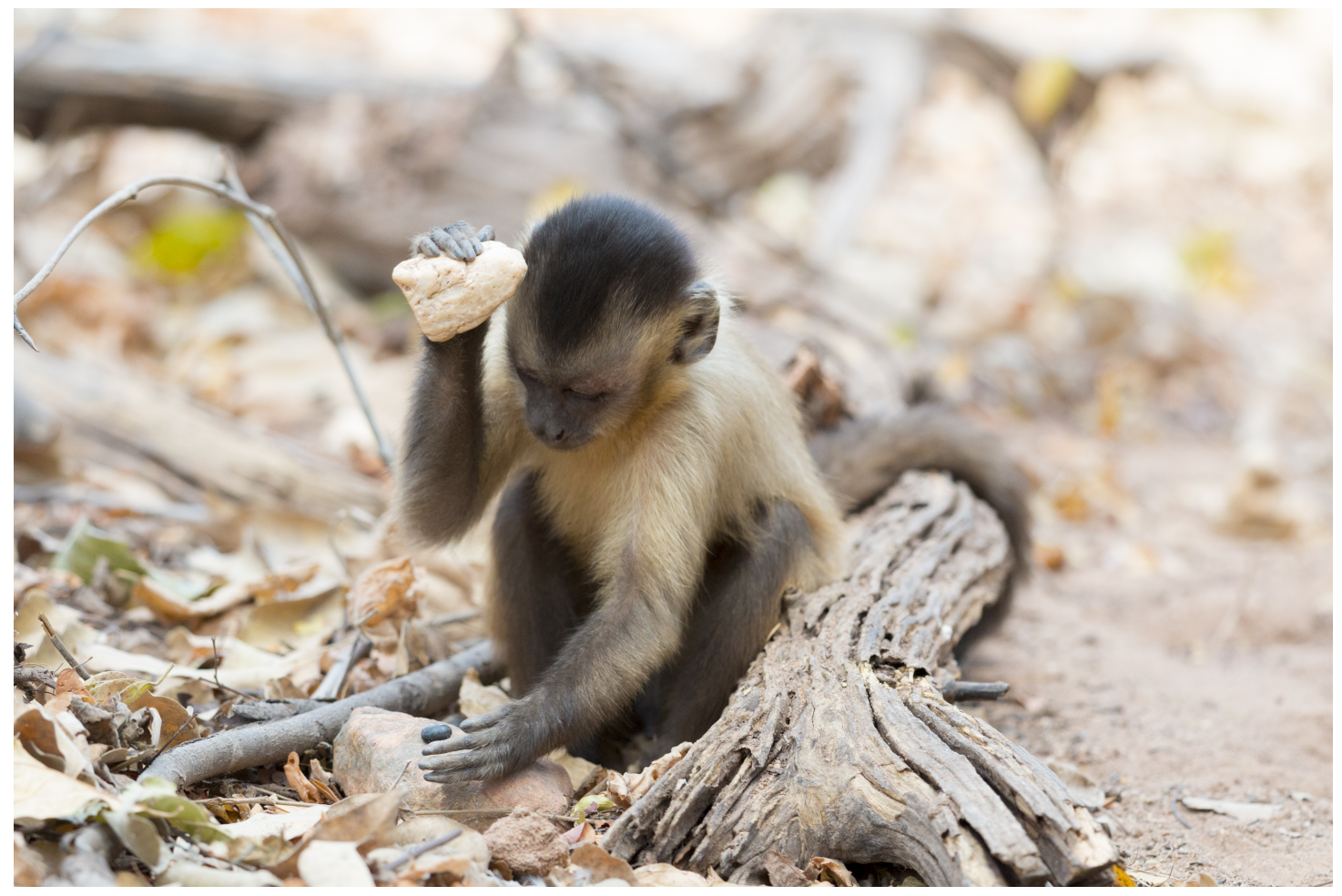

A juvenile capuchin monkey (Sapajus libidinosus) using a stone as tool to open a seed. The capuchin population from Serra da Capivara has the most complex tool set known for neotropical primates. Image by Tiago Falótico, CC BY-SA 4.0 from Wikimedia Commons.

The other question that emerges is how our ancestors knew which ferments were safe? This really comes to a head in the context of work by Dan Fisher at the University of Michigan. Dan has found evidence 12,000 years ago Clovis people in Michigan, and thereabouts, may have butchered mastodons with stone tools and then moved them into ponds and lakes where they were fermented for months. $\underline{1}$ This would have made the mastodon meat available throughout the winter. The way Dan approached this study was to first document archaeological sites where it looked as though this had happened. Next, then he followed up by recreating the process, not with a mastodon, but with a horse. Dan made stone tools, used those stone tools to butcher the horse, and then he put the horse in a pond. He went back to check on it over months. What's amazing about this experiment, other than that Dan did it, is that five months later, 
when he decided the experiment was done (because the meat had started to pull apart and spread through the pond making it hard to reach all of it) the meat had a flavor like Stilton cheese and steak, all in one. And it was sour. This suggests that you could make a delicious ferment just by rolling a butchered mastodon into a lake. It goes back to that second question: how would you know if this was safe? How would you make it safe? The most obvious answer is that our ancestors relied on their smell library to learn the good smells associated with a good ferment, and to learn the bad smells associated with a bad ferment, and then to build on those so that they knew they were doing the right thing. We learn pretty good smells very quickly and we learn bad smells really quickly. If a food makes you sick, say to vomit, you will learn in one instance to associate the smell of the food with a dislike for that smell. It's called the Garcia effect. Some poor guy named Garcia discovered it and now, it bears his name. We can imagine this played a very important role in sorting out good ferments from bad ferments.

Our work and the work of other labs has begun to show the intimate relationship between ferments and people's bodies. The microbes from fermentation can colonize people's bodies and the microbes from people's bodies colonize their fermentations. Therefore we might also imagine that as people are learning to love certain fermentation smells, those are also the daily smells of their own bodies. There's this intimate knowing of the food and the people that is probably more important than we think. We can imagine that one learns the right smell (the bodily smell of a good ferment), and then acts to engender that smell which, in turn, becomes encoded in rituals and norms. Much as doctors could once sniff out a sick patient, cooks could sniff out a bad ferment.

There is one other element that important and that is sour taste. While writing the book, it became clear that there wasn't a single paper that had ever attempted to comprehensively explain the evolution of sour taste and what it does. There were two paragraphs in a paper written by Paul Breslin that considered what sour taste does, but that was all we could find. Therefore, we pulled together a team of people to consider what we know about sour taste, what we can learn from it, and whether it bears in any way on our understanding of fermentation. Each of the people involved in the project has a different special skill. Kurt Schwenk is an expert in taste in reptiles. Emily Liman recently discovered our taste receptor. Paul Breslin has looked at the evolution of taste in general. Katie Amato was also involved. It is a super team. What we hoped we might initially do was to take a look at the new protein and its genes, the new sour taste receptor, that Emily had discovered. We could look at how it evolved 
through time as a measure of how our sour taste has changed and then see if the evolutionary trajectory matched up in any way with consumption of foods that might be fermented. However, the trick with this, and why we couldn't do it, is that same protein and its gene also does lots of other things in the body. Therefore, it can't be used to trace the evolution of sour taste, not on its own, anyway. Instead, we searched the literature for any studies where people had looked at particular vertebrates, and whether they could detect acidity in their food, and how they responded to it. We compiled a list of which ones can detect acidity and which can't. In fact, we found that all of the species we looked at could detect acidity in their foods. Therefore, as far as we know, all vertebrates can detect sour. It could be that the ones that can't have just not been studied, but we don't know. The second step was to consider which of these species like acidic foods. In some of the top groups we studied-amphibians, reptiles, birds, marsupials, bats - none of the species liked acidic foods, even slightly acidic foods. Within the ungulates, there was a little bit of variation. Therefore, pigs and goats appear to at least sometimes like acidic foods. That was intriguing. None of the rodents and or rabbits appeared to like acidic foods. When we considered our own group, the primates, we found a lot of variation. Some primates clearly like acidic foods, including humans, chimpanzees, and night monkeys.

Therefore, the primate story seems very different from the story of the rest of these species. Why might this be? What Paul Breslin has argued, and we reiterate, is the possibility that part of this story relates to vitamin C. Primate ancestors lost the ability to produce vitamin $\mathrm{C}$, which, we imagine, predisposes them to needing more vitamin $\mathrm{C}$ from their diets. Perhaps in some contexts, therefore, it becomes important to like sour or like acidity, because it can sometimes be an indication of ascorbic acid, which is vitamin C.

A question germane to our story today is, what were the consequences of primates liking of sour things? Liking sour taste possibly allowed our ancestors and other primates to use the tongue like a $\mathrm{pH}$ test paper, but then also to use it to find which things were potentially good and safe. This becomes clearer in the context of recent work by Erin McKenney. Erin has led this beautiful paper in which she's considered fermentation of a series of different kinds of sourdough breads. She has found that over the course of making a sourdough starter, the lactic acid bacteria become more common over the course of a few days. No huge surprise, but very, very consistent. 
The other thing she found is that as the lactic acid bacteria become more common, the sourdough becomes more acidic. It also becomes safe. When it gets to that $\mathrm{pH}$ of 4 , most of the foodborne pathogens that might be present are gone.

Using sourdough as an example, if our ancestors used their tongues, and supplemented with their noses, to assess

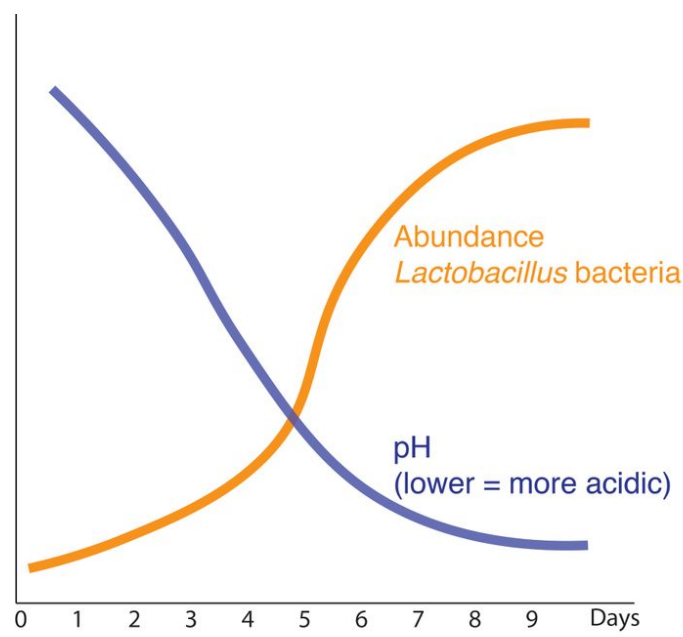
fermentation, they have a way to figure out whether the fermentations is good and whether it is safe, all built into their sensory systems. It is noteworthy that fermented horse had a flavor like Stilton cheese and steak all in one. And that it was sour. We can then imagine that one could learn the right smell of a good ferment, and could learn the acts that engender that smell which, in turn, become encoded in rituals and norms. Much as doctors could once sniff out a sick patient, cooks could sniff out a bad ferment. And just to make sure, the tongue also checks acidity.

What we want to do now is to engage you in an endeavor in which we're going to see what people practice- fermentation today. What do you use as a judge of the safety of your ferment? How do you judge whether your ferment is good? How do you judge if it's safe? What are the characteristics of a good or bad ferment? What does traditional kitchen knowledge teach us about what our ancestors might have been able to do? We'll be starting this project soon. If you have ideas about how to do this or things you would like to see asked, feel free to email us.

We have not fully resolved any of the mysteries of our evolution or the mystery of fermentation. But I hope that I've given you a little sense of why considering flavor shines a new light on some of these mysteries. All the stories I've told today are considered in more detail in the book, along with all these other things I'd like to talk more about, like avocados and spices, but I won't talk about today.

\section{Footnotes}

1. Read more about Dan Fishers work in Sapiens article Could Mammoth Bones $\underline{\text { Reveal When Humans First Arrived in North America? }}$ 


\section{Citations}

1. William Carlos Williams, "This Is Just to Say" from The Collected Poems: Volume I, 1909-1939, copyright @ 1938 by New Directions Publishing Corp. $\_$

2. William Carlos Williams, "“To a Poor Old Woman"" from Collected Poems: 19091939, Volume I copyright 1938 by New Directions Publishing Corp. $\_$

3.

Li Liu, Jiajing Wang, Danny Rosenberg, Hao Zhao, et. al.

Fermented beverage and food storage in 13,000 y-old stone mortars at Raqefet Cave, Israel: Investigating Natufian ritual feasting.

Journal of Archaeological Science: Reports, Vol. 21, 2018, pp. 783-793.

doi.org/10.1016/j.jasrep.2018.08.008 